\title{
MICROPOLÍTICAS DAS PRÁTICAS COTIDIANAS: ETNOGRAFANDO UMA ORGANIZAÇÃO CIRCENSE
}

\author{
MICROPOLICIES OF DAY-TO-DAY PRACTICES: CONDUCTING ETHNOGRAPHY IN A CIRCUS \\ ORGANIZATION
}

MICROPOLÍTICAS DE LAS PRÁCTICAS COTIDIANAS: ETNOGRAFIANDO UNA ORGANIZACIÓN CIRCENSE

\section{RESUMO}

Neste artigo, analisamos como as práticas cotidianas podem ser compreendidas com base na dimensão micropolítica dos processos organizacionais. As discussões teóricas articulam diálogos entre Michel de Certeau e Michel Foucault nos estudos sobre as práticas cotidianas, e a opinião de Theodore Schatzki sobre as organizações como espaços praticados. Baseadas em uma etnografia realizada em um circo, com 25 anos de existência, identificamos práticas de gestão que proporcionaram a emergência dos sujeitos produtores culturais e a forma- ção de redes associativas do circo com empresas, em decorrência da existência de demanda de atividades artísticas por parte do mercado. Também observamos gestos políticos das artes circenses nas discussões sobre a recepção dos espetáculos pelo público e a formação do circo-escola e de projetos de cunho social realizados pelo circo. Por fim, consideramos o cotidiano organizacional como um espaço de práticas que constituem micropolíticas em meio à esfera normativa dos processos de gestão.

PALAVRAS-CHAVE Práticas cotidianas, cotidiano organizacional, micropolíticas, etnografia, circo.

Josiane Silva de Oliveira oliveira.josianesilva@gmail.com

Doutoranda em Administração de Empresas pelo Programa de Pós-graduação em Administração da Universidade Federal do

Rio Grande do Sul - Porto Alegre - RS, Brasil

Neusa Rolita Cavedon nrcavedon@ea.ufrgs.br

Professora Associada da Escola de Administração da Universidade Federal do Rio Grande do Sul - Porto Alegre - RS, Brasil

Abstract In this article, there is an analysis of how day-to-day practices can be understood as being based on a micropolitical dimension of organizational processes. The theoretical discussions combine the dialogue between Michel de Certeau and Michel Foucault in their studies of day-to-day practices with the opinions of Theodore Schatzki about organizations as designated spaces. On the basis of an ethnographical study conducted in a circus that has been in operation for 25 years, we discovered management practices that allowed cultural subjects/ producers to emerge and networks that had been set up to link the circus with companies, as a result of the demand for artistic activities in the market. We also observed policy measures with regard to circus arts, in discussions about the way the shows were perceived by the public, and the formation of a circus school and projects of a social nature carried out by the circus. Finally, we examine their organizational day-to-day life, as a space for practices that constitute micropolicies, within the sphere of normative management procedures.

keywords Everyday practices, organizational everyday life, micropolicies, ethnography, circus.

Resumen En este artículo, analizamos cómo las prácticas cotidianas pueden ser comprendidas con base en la dimensión micropolítica de los procesos organizacionales. Las discusiones teóricas articulan diálogos entre Michel de Certeau y Michel Foucault en los estudios sobre las prácticas cotidianas, y la opinión de Theodore Schatzki sobre las organizaciones como espacios practicados. Basados en una etnografía realizada en un circo, de 25 años de existencia, identificamos prácticas de gestión que proporcionaron la emergencia de los sujetos productores culturales y la formación de redes asociativas del circo con empresas, resultantes de la existencia de demanda de actividades artísticas de parte del mercado. También observamos gestos políticos de las artes circenses en las discusiones sobre la aceptación de los espectáculos por el público y la formación del circo-escuela y de proyectos de carácter social realizados por el circo. Finalmente, consideramos la rutina organizacional como un espacio de prácticas que constituyen micropolíticas en medio a la esfera normativa de los procesos de gestión.

Palabras clave Prácticas cotidianas, rutina organizacional, micropolíticas, etnografía, circo. 


\section{INTRODUÇÃO}

Objetivamos, neste estudo, analisar como as práticas cotidianas podem ser compreendidas com base na dimensão micropolítica dos processos organizacionais. Para tanto, realizamos um estudo etnográfico em uma organização circense. A temática das práticas vem despertando crescente interesse nos estudos organizacionais (SCHATZKI, 2006). Estudos sobre epistemologia em Administração (CORRADI, GHERARDI, VERZELLONI, 2010; SCHATZKI, 2005), aprendizagem organizacional (ANTONELLO e FLACH, 2011; YAKHLEF, 2010), estratégia (LEITE-DA-SILVA, CARRIERI, SOUZA, 2011; SARAIVA e outros, 2011), têm enfatizado, por meio de diferentes abordagens, o caráter processual das práticas nas organizações.

Não obstante, a literatura em estudos organizacionais ainda apresenta uma lacuna teórica no que concerne aos efeitos políticos das práticas no cotidiano dos sujeitos sociais. No intuito de colocar em discussão essa perspectiva de análise, fizemos uma escolha teórica que busca entender o cotidiano organizacional como um espaço de práticas - constituindo micropolíticas - em meio à esfera normativa dos processos de gestão. Ademais, este estudo justifica-se pela possibilidade de colocar em discussão três filósofos: Michel de Certeau e Michel Foucault, nos estudos sobre o cotidiano; e Theodore Schatzki, sobre as organizações como espaços praticados, cujas obras, ao serem entremeadas no campo de pesquisas em Administração, oferecem elementos analíticos aos processos de gestão.

Compreendemos micropolíticas como processos organizativos em um espaço de práticas (FOUCAULT, 2010; SCHATZKI, 2006), Os quais, ao atrelarem-se à esfera de normatividade social, confrontam, mesmo que sob a aparência de reprodução, um ordenamento social de modo a transgredi-lo (CERTEAU, 2002). As micropolíticas: a) referem-se às relações da reflexividade, do confronto, das práticas com lógicas de ação determinadas desde uma perspectiva histórico-cultural; b) apresentam um cunho processual, pois as formas de organização são múltiplas e articuladas em um espaço de práticas; c) produzem efeitos no cotidiano, devido ao seu caráter relacional com as esferas normativas da sociedade.

O estudo etnográfico aqui apresentado tem sido desenvolvido em um circo, cujo processo organizacional ainda se faz pouco explorado nos estudos organizacionais (PARKER, 2011; COSTA, 2000). A re- ferida organização, localizada na cidade de Pelotas, distante 300 quilômetros da capital do Estado do Rio Grande do Sul, foi fundada em 1987 e tombada como patrimônio cultural do Estado no ano de 2007. Atualmente, o circo possui aproximadamente 100 pessoas diretamente implicadas em suas atividades, sendo 32 artistas atuantes em dois espetáculos circenses, um deles em cartaz há 10 anos, com mais de um milhão de espectadores em nove estados brasileiros.

As reflexões, alicerçadas na base teórica, sobre os achados de campo estão organizadas em cinco tópicos, além desta introdução. Primeiramente, discutimos teoricamente o cotidiano como um espaço de práticas, e as práticas em sua dimensão micropolítica como processos constituintes das organizações. A seguir, apresentamos os circos como espaços organizacionais, e, imediatamente, os procedimentos metodológicos da pesquisa. No quarto tópico, apresentamos as análises dos dados de campo e, ao final, as reflexões de cunho teórico-empíricas decorrentes do estudo realizado.

\section{COTIDIANO COM BASE EM UMA DIMENSÃO MICROPOLÍTICA}

Muito embora exista uma dimensão de reprodução social no cotidiano, é preciso salientar a constituição de práticas contraditórias nesse espaço. Há uma dimensão produtora de articulações na sociedade, e a preocupação na esfera política cotidiana apresenta-se na capacidade de dispersão das práticas em relação à esfera normativa da sociedade (CERTEAU, 2002). É preciso considerar o cotidiano levando em conta as articulações entre as denominadas esferas macro e micro das ações sociais.

Certeau (2002) e Foucault (2010), ainda que não diretamente, empreendem um embate teórico acerca dos estudos sobre o cotidiano. Para Foucault (2006), as análises do cotidiano implicam o entendimento das redes de disciplinas que caracterizam a ordem social e as tecnologias de poder presentes nas ações dos sujeitos. Os sujeitos vivenciam material e simbolicamente o cotidiano, pois eles participam de sua elaboração e do exercício dos efeitos das relações de poder (FOUCAULT, 2006). O poder, apoiado na produção de espaço e tempo, constitui o cotidiano, bem como a emergência de saberes (FOUCAULT, 2010). 
Esses saberes articulam formas específicas de relações de poder, a exemplo das práticas disciplinares (FOUCAULT, 2006), que permitem o controle minucioso do corpo, da subjetividade, garantindo uma relação de docilidade e utilidade dos sujeitos na sociedade capitalista. Para Foucault (2010), o poder é uma prática social constituída historicamente e exercida em diferentes formatações, e seus efeitos intervêm materialmente na realidade dos sujeitos, a exemplo do corpo biológico e socializado, caracterizando mecanismos micropolíticos de manifestação no espaço social.

As posições ocupadas no espaço formam os lugares, que são pontos de ancoragem para a constituição das práticas que sustentam os mecanismos das relações de forças, bem como configuram as formações dos sujeitos (FOUCAULT, 2010). Essa é uma das características das práticas disciplinares para Foucault (2010), pois, nesse espaço, os indivíduos são classificados e hierarquizados, segundo diferentes objetivos, para garantir sua funcionalidade.

A intervenção dos sujeitos no espaço ocorre nas modificações das relações de forças, podendo tornar intolerável o efeito do poder propagado espacialmente e do funcionamento das técnicas disciplinares (FOUCAULT, 2006). As formas de distribuição desses entrecruzamentos das relações de forças constituem as políticas das práticas cotidianas, que se caracterizam pelo confronto com a história do presente e pela constituição dos sujeitos (FOUCAULT, 2010). Para Castro (2008), Michel Foucault caracterizava as práticas como: (1) modos organizados das maneiras de fazer dos sujeitos sociais; (2) configuradoras de uma sistematicidade; e (3) compostas por uma generalidade, uma configuração histórica singular.

Para Certeau (2002), as políticas compreendem as formas de mobilização social no espaço que podem ser articuladas em tecnologias de poder, mas que também podem perturbar o estabelecimento de uma ordem. Por espaço, Certeau (2002, p. 202) entende "[...] o efeito produzido pelas operações que orientam, circunstanciam, temporalizam e levam a funcionar os elementos móveis de uma unidade polivalente de programas conflituais ou de proximidades contratuais [...]". No que se refere a lugar, Certeau (2002, p. 201) assinala como "[...] uma ordem de distribuição que configura posições instantâneas e estabilidade [...]". O lugar enseja o exercício de ações em relação ao "outro", resultando no estabelecimento do próprio. O conceito de próprio refere-se à vitória do lugar sobre o tempo, sobre a possibilidade de estabelecer uma ordem em um espaço de mobilidade (CERTEAU, 2002).

O espaço é o lugar praticado por sujeitos históricos, uma vez que, em meio a essas tramas, os sujeitos podem estabelecer intervenções de sustentação ou rupturas das tecnologias do poder, criando outros lugares que não os próprios em um espaço (CERTEAU, 2002). Se, para Foucault (2006), as relações de poder formam as tecnologias disciplinares, para Certeau (2002), é no cotidiano que devemos analisar esse processo, dado que ele não está submetido tão somente ao nível disciplinar mas também à dimensão política das práticas cotidianas.

De acordo com Certeau (2002), as práticas cotidianas são as "maneiras de fazer" pelas quais os sujeitos se apropriam do espaço social. Por isso, Certeau (1985) afirma o triplo caráter dessas práticas: o estético, determinado pelo estilo de fazer dos sujeitos sociais; o ético, em que a recusa à identificação com a ordem estabelecida abre espaços para criações nas ações; e o polêmico, caracterizado pelas intervenções nas relações de forças. A dimensão micropolítica das práticas no cotidiano refere-se às ações dos sujeitos que, em meio à esfera de normatividade social, podem, até mesmo sob a aparência de reprodução, transgredir ou estabelecer outros processos de organização social imbricados nas condições de existência vigentes (CERTEAU, 2002).

Certeau (2002) considera a existência de saberes em práticas que não são ditas nem ensinadas, tampouco pertencentes ao domínio de uma suposta inconsciência dos sujeitos. Pode haver uma lógica de ação articulada nas condições de possibilidades históricas das práticas que transgride a ordem estabelecida, ou mesmo as representações dessas ações em contextos específicos, como na administração de empresas (CERTEAU, 2002). É isso que Foucault (2010) denomina efeito, algo que é produzido pelas práticas, mas que não está em seu domínio.

Sob esse enfoque, Certeau (2002) afirma a relevância de se compreenderem as maneiras de fazer o cotidiano pelos sujeitos sociais com base na distinção dos estilos de ação em contextos específicos. Essa concepção de práticas como articulação de ações aproxima as discussões de Michel de Certeau e Michel Foucault em relação ao estudo das práticas nas organizações discorrido por Theodore Schatzki, autor que postula as organizações como espaços praticados. O próximo tópico tem por objetivo discutir como essa noção de práticas do cotidiano pode 
contribuir para a politização dos estudos sobre as práticas organizacionais.

\section{PRÁTICAS NAS ORGANIZAÇÕES EM UMA DIMENSÃO MICROPOLÍTICA}

Os estudos das organizações por meio das práticas têm problematizado como, no cotidiano de trabalho, se estabelecem processos e lógicas de ação em diferentes espaços de atuação (SANDBERG e DALL'ALBA, 2009). Para Gherardi (2010), as práticas são analisadas com base nas atividades em ação, sua temporalidade e processualidade, possibilitando que as organizações aconteçam. Para Schatzki (2006), o "acontecimento das organizações" envolve o entendimento filosófico da temporalidade, implicando reflexões sobre o que venha a ser tempo objetivo e tempo teleológico.

O tempo objetivo corresponde às performances definidas pela lógica da eficiência, sendo as práticas consideradas, desde sua exterioridade, como padrões de atividades e normas de sustentação social (SCHATZKI, 2006). É a vitória do lugar sobre o tempo que constitui o "próprio" nas discussões de Certeau (2002). Para Foucault (2010), o controle do tempo é característico das práticas disciplinares. Ao submeter o corpo ao tempo, essa objetivação estabelece um processo de sujeição, produzindo eficácia aos gestos dos sujeitos, sendo o corpo um objeto passível de manipulação (FOUCAULT, 2010). O controle do tempo possibilita analisar as formas mais elementares das relações de poder (FOUCAULT, 2010).

Para Schatzki (2006), o tempo teleológico diz respeito ao caráter de confronto social e está incorporado nas práticas cotidianas, possibilitando tornar aceitável um conjunto de ações que constituem as organizações. Essas duas temporalidades estão presentes no acontecimento organizacional, não sendo possível estabelecer uma clivagem do contexto socioeconômico, pautado na eficiência, ou disciplinar a temporalidade de modo que os sujeitos não possam atuar além dela, politizando as práticas. Para Foucault (2006), como o poder é uma prática exercida, qualquer luta é sempre resistência, especialmente no controle da temporalidade.

Schatzki (2005) afirma que as ações humanas são organizadas por meio de práticas. Essas maneiras de fazer referem-se a um determinado contexto, como os locais de trabalho. Os contextos de atuação das ações humanas são denominados site, ou lugar. Um contexto pode ser entendido como uma arena ou um conjunto de disposições de fenômenos. As ações ocorrem em determinados contextos e produzem espaços, proporcionando uma dinâmica de mobilidade nesse conjunto de disposições. Os lugares, ou sites, são formados pelos nexos das práticas dos sujeitos em face de um contexto, articulando-os aos arranjos materiais. Esses últimos compreendem a dimensão objetiva constituinte dos lugares por meio de uma configuração com as práticas. As organizações são entendidas como arranjos-práticos situados sócio-historicamente (SCHATZKI, 2006).

As críticas a essa proposição de análise organizacional de Theodore Schatzki referem-se à não sistematização das contradições das práticas que configuram lugares de decisão nas organizações (CERTEAU, 2002), bem como às relações de poder (FOUCAULT, 2006). Portanto, aproximando teoricamente Certeau (2002), Foucault (2010) e Schatzki (2006), é possível estabelecer um caminho para o entendimento das contradições de análise das práticas cotidianas nas organizações. Para Schatzki (2005), Certeau (2002) e Focault (2010), são as práticas que organizam espaçotemporalmente as ações humanas e tecem os cotidianos, possibilitando constituir as lógicas de ação dos sujeitos sociais.

As práticas são apresentadas por Certeau (2002) em dois arranjos: as estratégias e as táticas. Para o referido autor, as estratégias são manipulações de relações que possibilitam isolar sujeitos de saber e poder circunscrevendo lugares próprios de onde é possível gerir relações com uma exterioridade de alvos:

\footnotetext{
Como na Administração de empresas, toda racionalização "estratégica" procura em primeiro lugar distinguir de um "ambiente" um "próprio", isto é, o lugar de poder e de querer dos próprios. Gesto cartesiano, quem sabe: circunscrever um próprio num mundo enfeitiçado pelos poderes invisíveis do Outro. Gesto da modernidade científica, política ou militar (CERTEAU, 2002, p. 99).
}

A vitória sobre o tempo permite capitalizar ganhos para as ações futuras das estratégias, estabelecendo relações de poder que postulam o controle dos lugares de decisão (CERTEAU, 2002). Para Certeau (2002), nos locais de trabalho, difundem-se técnicas culturais de controle que dissimulam a reprodução econômica por meio de ficções de surpresas, de verdades ou de comunicação. Foucault (2006) destaca as práticas 
disciplinares por meio da vigilância como um dos principais meios de controle dos sujeitos. A exposição contínua e permanente às técnicas de vigilância, como o panóptico, deve ser difundida de modo que quem é vigiado incorpore a visão de quem observa (FOUCAULT, 2006). Essa captura estratégica caracteriza as relações de trabalho capitalistas, configurando subjetividades construídas e vividas pelos sujeitos em meio às tecnologias de poder (FOUCAULT, 2010).

As táticas caracterizam-se pela ação calculada, determinada pela ausência de um próprio (CERTEAU, 2002), atuando no campo do "outro" e no espaço por ele controlado. As táticas não capitalizam a temporalidade, atuando em um tempo teleológico (SCHATZKI, 2006) que não estabelece um lugar próprio de ação, permitindo mobilidade e improvisação. Certeau (2002) ainda afirma que as táticas não estabelecem projetos globais de totalização de um espaço visível e objetivado (como os lugares de decisão), mas operam golpe por golpe, lance por lance, como em uma caça furtiva.

O desdobramento dos efeitos desses arranjos de práticas (estratégias e táticas), ao persistirem nas temporalidades (objetivo e teleológico), configuram as organizações (SCHATZKI, 2006). A objetivação desse processo está imbuída nos arranjos materiais dos contextos organizacionais, o que inclui a materialidade do corpo humano como desdobramento do fenômeno organizacional (FOUCAULT, 2006). É por isso que existem construções de práticas que não podem ser ditas nem ensinadas, mas, sim, colocadas em ação (CERTEAU, 2002). Elas se formam e se disseminam na sociedade sem a necessidade de um saber próprio, não sendo possível discutir práticas que produzem subjetividades sem postular suas formas de objetivação (FOUCAULT, 2010).

Essa articulação subjetivo-objetiva confere às práticas o caráter de organização e organizadoras, implicando uma dimensão de positividade no cotidiano dos sujeitos (FOUCAULT, 2010). Por meio das micropolíticas, faz-se possível confrontar os processos organizacionais de mobilização do social, pois esse ordenamento articulado diz respeito a um espaço de práticas que são exteriores ao cotidiano das organizações e que o interpelam. Assim como Sato, Bernardo e Oliveira (2008), consideramos relevante destacar as ações configuradoras de determinados arranjos no cotidiano de trabalho, em que estão as práticas que podem transgredir silenciosamente a ordem estabelecida.

Como exemplo, Certeau (1999) discorre sobre o que se tem denominado produção cultural, pois essa divisão social do trabalho oferece um campo de expansão das análises das operações estratégicas de práticas de gestão. A seguir, o circo será pensado sob a sua dimensão organizacional, de modo a contribuir para o entendimento da parte empírica que será analisada mais adiante.

\section{CIRCO COMO ORGANIZAÇÃo}

A apropriação que as organizações que trabalham com práticas circenses têm realizado das formas de vida contemporânea, a exemplo da hibridização artística, possibilita empreender um debate a respeito dos diferentes usos da subjetividade humana nos espaços organizacionais. Ademais, atentar para os circos como objeto de estudos também possibilita pensar sobre articulações entre a produção artística e as práticas de gestão.

Como espaço organizacional, as artes circenses são entendidas com base em sua constituição por meio de circos, apresentando seus primeiros fragmentos com espetáculos nômades e pagos no período da Revolução Industrial na Inglaterra (PARKER, 2011). A estrutura organizacional circense, em seus primórdios, era familiar e nômade, e as técnicas eram aprendidas e desenvolvidas por transmissão oral (OFEN, 2010). No Brasil, as práticas circenses chegaram por volta do século XX, trazidas por imigrantes europeus (SACCO e BRAZ, 2010). Também nesse período, não foi estabelecido um saber científico (FOUCAULT, 2010) sobre o circo, o que lhe confere um saber marginal em relação às outras artes e atividades organizacionais já articuladas no e com o campo científico. Os circos eram manifestações artísticas marginais direcionadas a grupos populares e apresentadas nas periferias das cidades no Brasil (SACCO e BRAZ, 2010), portanto não havia um lugar próprio (CERTEAU, 2002) estabelecido pelos circenses no País.

Em termos de atividade econômica, os circos são considerados organizações constituintes das denominadas indústrias criativas (BENDASOLLI e BORGES-ANDRADE, 2011; BENDASSOLLI e outros, 2009). De acordo com dados do Instituto Brasileiro de Geografia e Estatística (LINS, 2007), no Brasil, nos anos de 1970, havia mais de duas mil companhias circenses espalhadas pelo País; já no ano 2000, não passaram de 300 circos, e, nesse mesmo período, a quantidade de circos-escola aumentou de dois para 40. 
O projeto de lei n. 397/2003 (LINS, 2007), em trâmite no Congresso Nacional Brasileiro, em seu artigo segundo, define circos como espetáculos que possuam mais de $50 \%$ de suas práticas relacionadas às chamadas atividades circenses. Os aparelhos utilizados nessas atividades são, por exemplo, tecidos, trapézio, perna de pau e lira, desenvolvidos com base em performances como acrobacias, malabarismo, mágicas, equilibrismo, palhaços, clown e pirofagia (SACCO e BRAZ, 2010). As apropriações das atividades circenses vão constituí-las como práticas e estabelecer diferentes formas organizacionais de circo. Temperani (2011) considera o circo uma arte cênica, caracterizando um espetáculo como organização circense com base nas descrições expostas no Quadro 1.

As trupes são organizações circenses caracterizadas pela constituição de grupos de artistas de diferentes formações que se utilizam das práticas circenses em suas atividades. Centrada na expressividade da linguagem artística híbrida, a lona, trailers e demais estruturas físicas do circo nômade já não compõem as trupes circenses, que passam a se apresentar em teatros, ginásios ou mesmo nas ruas. É essa configuração organizacional de trupe circense, que tem no teatro a sua maneira mais recorrente de apresentação, que este artigo foca.

\section{MÉTODO}

Como método de pesquisa, utilizamos a etnografia. Inicialmente desenvolvidos no campo da antropologia, os estudos etnográficos já foram incorporados aos estudos organizacionais, por meio de diversas pesquisas (ALCADIPANI e ROSA, 2012; JAIME, 2002; CAVEDON, 1988). Clifford (2008) assinala que a etnografia consiste no envolvimento direto com os participantes e o campo de pesquisa, em que a operacionalização etnográfica remete, em termos físicos e intelectuais, às vicissitudes da tradução. Em novembro de 2010, uma das pesquisadoras deste trabalho (Ana) entrou em contato com os diretores do circo - o Grupo Tholl - e a realização da etnografia foi autorizada formalmente. A pesquisa foi realizada de março a dezembro de 2011. Ana acompanhou o dia a dia das atividades do circo em estudo em diferentes espaços organizacionais: $\mathrm{O}$ Centro de Treinamentos (CT), o ateliê, as viagens para apresentações dos espetáculos e atividades para além do cotidiano de trabalho dos artistas.

Do método etnográfico, destacaram-se as técnicas da observação participante, com as descrições registradas em diários de campo, e entrevistas de histórias de vida. A observação participante consiste, para Clifford (2008), no envolvimento do pesquisador com as atividades de seu campo de pesquisa, de

\section{Quadro 1 - Processos organizacionais circenses}

CATEGORIA

Circo teatro

Circo itinerante

Circo escola

Circo social

Circo de rua

Grupos e trupes circenses

Números/performances circenses

\section{DESCRIÇÃO E ESTRUTURA DE APRESENTAÇÃO}

Espetáculos em dois atos. 0 primeiro com atividades circenses e o segundo com 0 teatro. Apresentações em Ionas ou teatros, podendo ser itinerantes.

Espetáculos compostos por números circenses. Apresentam-se em lonas, sendo itinerantes. Divididos em três categorias: circo pequeno: até 500 lugares; circo médio: até 1.000 lugares; circo grande: acima de 1.000 lugares.

Formação de artistas profissionais visando a sua inserção no mercado de trabalho. Estrutura fixa para os processos de aprendizagem.

Utiliza-se das artes circenses para o desenvolvimento de atividades de cunho social, cultural, pedagógico e educativo. Estrutura de lona e não itinerante.

Composto por artistas de diferentes formações profissionais. Estrutura-se com apresentações em espaços públicos.

Composto por artistas com principal formação nas artes circenses. Apresentam-se em teatros e espaços alternativos e possuem locais fixos de treinamento.

Conjunto de "trucs" obedecendo a uma sequência lógica, com coreografias e trilha sonora. Sem estrutura definida para as apresentações.

Fonte: Adaptado de Temperani (2011). 
modo que sua própria agenda de trabalho se torna as atividades do grupo em estudo. Ana participou das aulas e treinamentos realizados no circo. Durante as primeiras observações, os artistas a convidavam para participar dessas atividades, e, em alguns momentos, eles improvisavam ações nas aulas de modo que Ana pudesse ser envolvida, sendo, posteriormente, reconhecida pelas atividades com malabares e trabalhos de contrarregra nos espetáculos.

Ana ouvia várias histórias de como transcorria o processo de se viver como um artista circense, visto que, dos 32 sujeitos pesquisados, apenas um é originário de família circense, de nacionalidade argentina. Falas atinentes à mudança de vida, aos conflitos diante dessa escolha de trabalho e sobre serem taxados como loucos pela sociedade foram recorrentes durante o estudo. Essas colocações reveladas pelos diferentes sujeitos não se limitaram a ser direcionadas aos artistas circenses, mas também foram dirigidas para Ana, quando ela fazia comentários nos espaços acadêmicos sobre sua pesquisa. Com isso, optamos por realizar entrevistas de histórias de vida (CLIFFORD, 2008), pois era possível observar que certas práticas cotidianas eram interpeladas por discursividades.

As entrevistas, realizadas com os 32 artistas circenses atuantes no Tholl, durante o processo etnográfico, seguiram um roteiro estabelecido pelos eixos temáticos: (1) trajetórias de vida (família, formação educacional e profissional); (2) trajetória no Grupo Tholl (ingresso e atividades desenvolvidas no grupo e nos elencos); (3) trajetória do Grupo Tholl, objetivando inscrever espaçotemporalmente a organização e os sujeitos. O roteiro de entrevistas foi adaptado de modo a respeitarmos as particularidades de cada um dos respondentes, buscando não interferir na ordenação da narrativa, bem como nos aspectos destacados como relevantes pelos pesquisados em relação a suas histórias de vida. Para a reprodução dos trechos das entrevistas, gravadas e transcritas, que consideramos necessários para a construção deste texto, os nomes utilizados são fictícios, inspirados no filme O palhaço (2011). As análises do estudo são interpretativas. Esse processo objetivou articular um espaço dialógico entre o teórico, o êmico e o ético. É uma interpretação de situações cotidianas, pois, como afirmam Dreyfus e Rabinow (2010), na analítica interpretativa, a "doença" que se quer tratar faz parte de uma epidemia que também afetou o pesquisador.

\section{GRUPO THOLL}

A Oficina Permanente de Técnicas Circenses (OPTC) foi fundada na cidade de Pelotas, Rio Grande do Sul, em 1987, por João Bachilli, ex-ginasta olímpico e ator. Ele convidou, na época, amigos para aprenderem técnicas circenses aos finais de semana. Entre estes, estava um grupo de capoeiristas, cujas técnicas foram incorporadas, posteriormente, em cenas dos espetáculos circenses. Como forma de financiamento do grupo, os artistas faziam atividades de animações em eventos para os quais eram contratados. No ano de 2002, o grupo estreou, na cidade de Pelotas, seu primeiro espetáculo: Tholl, Imagem e Sonho. E, a partir de então, foram denominados Grupo Tholl. Os espetáculos são montados e ensaiados no CT, localizado na região portuária pelotense. A montagem de palcos, de figurinos e de adereços é de responsabilidade de cada elenco. A concepção dos espetáculos é realizada por João, porém são criados coletivamente. Os artistas desenvolvem gratuitamente dois projetos: o circo-escola, onde ensinam técnicas circenses, cênicas e de dança em seu CT; e o Alegria Tholl, com atividades de animações em instituições na cidade de Pelotas. Atualmente, o Grupo Tholl funciona no regime de associação e possui três espetáculos em cartaz.

\section{As práticas cotidianas como produtoras de subjetividades nas artes circenses}

As modalidades de ação dos sujeitos sociais possuem um caráter político, pois se articulam com lógicas fornecidas pela conjuntura, circunstâncias que lhes são exteriores, mas que, diante de um "golpe de vista" (CERTEAU, 1985), estabelecem conjuntos de ações que podem transformar ou reproduzir a existência cotidiana. No contexto analisado, no processo de ingresso no circo, o cotidiano organizacional interpelou as subjetividades dos sujeitos, fragmentando o que era considerado referência de ação. Esse processo de apropriação evidenciou-se quando, questionados sobre suas respectivas trajetórias de vida, eles recorriam à organização em estudo para discorrer sobre tal questionamento, conforme observado nos seguintes relatos:

Eu entrei na faculdade no mesmo tempo em que estreou o Tholl, Imagem e Sonho [...] chegou um momento que eu tive que optar porque eu não estava conseguindo fazer nenhuma das duas coisas 
direito. Naquele momento, eu optei pelo trabalho que a gente tava fazendo, e a gente tava recém começando a viajar com o espetáculo e tal. E achei que seria interessante viver aquilo e num outro momento, depois, retornar à faculdade. O que aconteceu é que eu me apaixonei pelo que eu faço hoje, e acabou que eu não voltei e não voltaria (Benjamin, clown, 28 anos).

Na verdade, eu nem sabia que eu tinha tanto esse gosto por arte. Porque eu acabei me formando no colégio e decidi que queria fazer a faculdade de Administração [...] quando eu comecei a trabalhar no grupo e a animar, e olho no olho, sabe, foi aí que eu tive certeza de que era o que eu tinha que fazer. E no início foi difícil meu pai e minha mãe aceitar. [...] No início eu enfrentei: ah, eu acho muito lindo! Mas não pra minha filha, sabe! Eu adoro ir no circo, adoro ver aquela gente louca. Mas a minha filha vai ser administradora [risos]? (Justine, acrobata, 26 anos).

Ingressar no circo foi um momento de considerar as possibilidades de transgressão de uma ordem social imposta (CERTEAU, 1985), de configurar aberturas de espaços de atuações para além do trabalho. Essas ações, apesar de não romperem com a lógica econômica, pois o termo trabalho ainda é recorrente nas falas, atuam de maneira política, caracterizando-se pelo confronto com a história dos processos de constituição subjetiva vivenciadas pelos artistas até o momento de ingresso no circo (FOUCAULT, 2010).

A fala de Justine diz respeito ao questionamento de Certeau (2002) sobre a possibilidade de existência de um saber, nas práticas, desconhecido pelos praticantes. Corroborando as construções teóricas realizadas, essa dinâmica diz respeito aos efeitos do cotidiano organizacional (FOUCAULT, 2010), em que o domínio de ação do artista confronta as ações de "outros" (CERTEAU, 2002).

O cotidiano organizacional de viagens, de intervenções artísticas (animações) como os projetos Alegria Tholl e o circo-escola, e as interações sociais subjetivas ("olho no olho", "paixões") atuam como bricolagens em relação ao que era, até então, exterior a suas ações. São golpes que os sujeitos aplicam no sistema (CERTEAU, 2002). As modalidades de ação dos artistas em seu cotidiano podem ser analisadas pelas formas como estas são interpeladas pelos desdobramentos do cotidiano organizacional, como discute
Schatzki (2006), ao implicar formas de organização espaçotemporal das ações dos sujeitos.

O caráter político das modalidades de ação, articulado pelo cotidiano organizacional, demonstra que as práticas sociais dos artistas circenses foram alteradas em uma dimensão tática de atuação, ao considerarmos as expressões de opção de escolha pelo circo. Quando as conversas em campo se encaminhavam para esse processo de escolha, eram comuns expressões de indignação pelas dificuldades sociais que passavam, visto que, além de uma escolha profissional, era uma forma de viver entremeada ao circo. Ana foi observando que essas emoções começavam a fazer parte de seu cotidiano:

\begin{abstract}
Cheguei ao CT às $14 \mathrm{~h}$ para as aulas de tecido e acrobacias. A Guilhermina não aparecia nas aulas há uns dois dias. Quando estávamos todos reunidos para começar a aula, o Tony perguntou a ela o porquê das ausências. E ela respondeu: "eu não tinha dinheiro para o ônibus. Se eu sair da escola e for para casa a pé e voltar, não dá tempo de chegar no horário". Fiquei muito indignada! Depois, soube que eles a indicaram para fazer uns trabalhos de animações (diário de campo, 24 de maio de 2011).
\end{abstract}

Observamos que os artistas compartilhavam despesas, dividiam moradias, os empréstimos de dinheiro, sem taxas de juro, e compras coletivas em cartões de crédito também eram práticas comuns (diário de campo, 24 de maio de 2011). Eram formas de driblar o sistema econômico, dada a sua condição social. As determinações da sociedade, por meio de relações de poder, são objetivadas em um conjunto de sujeitos, como os pais, ao realizar a opção pelo circo; a estrutura educacional, pelo deixar a faculdade; ou mesmo a própria sociedade, por o artista não ter dinheiro para a sua locomoção até o CT. Esse caráter micropolítico das ações dos sujeitos, articulado à dinâmica social, nos possibilita tencionar o entendimento das modalidades de ação que circunscrevem e são circunscritas por práticas organizacionais no circo. A próxima seção de análises discute os processos das formalidades das práticas na organização em estudo.

\section{Práticas cotidianas nos processos organizacionais circenses}

As práticas de expressões artísticas articulam-se com e em práticas sociais. Essa dinâmica tem influenciado 
a constituição de outros processos organizacionais circenses, em especial, desde o final do século XX (PARKER, 2011). A incorporação de outras artes e técnicas desportivas, bem como uma estrutura organizacional não mais tão nômade e familiar, tem formado lugares próprios no âmago do circo, como observado nos seguintes relatos:

Foi quando eu entrei no grupo e tive contato com o Cirque Du Soleil [que reconheceu o Tholl como um circo] [...] E aí a gente sempre teve a pretensão de chegar ao nível do Cirque Du Soleil. E hoje em dia ainda é um pouco isso. Mas a gente quer botar a nossa cara na verdade. Mas é ter a fama que ele tem, a grandiosidade que ele tem, o apoio que ele tem do Estado, do Canadá, que apoia muito. É ser reconhecido aqui no Brasil (Robson, acrobata, 25 anos).

O circo tem cheiro de casca de arroz, tem cheiro de lona aquecida, tem cheiro de pipoca. Então, tem todo um aroma que antecede tudo, que eu acho que é muito específico assim. Se eu fosse cega, eu saberia facilmente se eu estou dentro de um circo ou não, entendeu? [...] E as apresentações, e o Tholl é uma prova disso, que o circo não necessariamente tenha que ser embaixo de uma lona e tal (Zaira, clown, 27 anos).

As modalidades de ação do cotidiano organizacional circense também são articuladas com práticas de gestão e interpeladas por relações de poder e de saber. As formalidades das práticas no circo em estudo, primeiramente, produzem um lugar para o circo "sem lona", pois, no que tange ao exterior a esse cotidiano de trabalho, as representações afirmam-se com base em práticas dos circos "com lona". É o efeito dos arranjos materiais nas organizações (SCHATZKI, 2006).

A referência de atuação do Cirque Du Soleil apresenta-se na fala de Robson como um cotidiano de trabalho com um solo comum de práticas para os circos "sem lona". Essa referência é perpassada por relações de poder ("chegar ao nível") e estabelecer um próprio do Grupo Tholl ("botar a nossa cara na verdade"), sujeitos de querer e de poder no espaço circense. Robson ainda salienta a intervenção do Governo canadense de modo a apoiar as atividades do Cirque Du Soleil, em que, para esclarecer tais relações, é necessário problematizar os meios pelos quais essas intervenções ocorrem, como defende Certeau
(1999). No caso do Grupo Tholl, este foi legitimado como patrimônio cultural do Estado do Rio Grande do Sul pelas esferas governamentais, mas, em termos de políticas de apoio às manifestações culturais dessa ordem, ainda não são observadas ações no sentido pleiteado por Robson.

Em termos de gestão, as formalidades das práticas circenses pautadas em apresentações "sem lona", ocorrendo em teatros e ginásios, desdobram-se na formação de redes associativas que podem se configurar como assimétricas (SCHATZKI, 2006). No caso dos teatros, a organização em estudo fica na dependência da existência de pautas, de datas específicas para apresentações e temporadas. As figuras dos produtores culturais inserem-se nesse cotidiano como mediadores das artes circenses. São eles que determinam a entrada ou não dos espetáculos em cartaz nos teatros. Com base nisso, se estabelece um sujeito de saber e de poder que, até então, não se fazia presente. Como discorre Foucault (2010), os sujeitos emergem em um espaço onde se operam práticas, portanto não há uma verdade a ser descoberta, ele é tal como aparece.

Durante a realização da pesquisa, a figura da Lola, produtora cultural do grupo, era apresentada pelos artistas como quem proporcionou outro movimento às atividades. Lola ingressou no Tholl no ano de 2005, sendo reconhecida como um braço de gestão que eles não possuíam até então (diário de campo, 13 de abril de 2011). Era ela quem mediava o agendamento de pautas nos teatros e com as produtoras, bem como a negociação com os contratantes dos espetáculos. Isso porque o Grupo Tholl viaja somente com espetáculos contratados ou agendados previamente. Essa formalidade de práticas indica como a lógica do discurso empresarial tem sido incorporada ao cotidiano de trabalho na organização.

Outro desdobramento desse cotidiano organizacional refere-se aos financiamentos. No caso do Grupo Tholl, por apresentarem um lugar de ação, a cidade de Pelotas, o grupo recebe um apoio financeiro de uma universidade privada da referida cidade para custear o CT. O galpão do CT foi cedido por uma empresa de transportes de Pelotas, no ano de 2010, quando o grupo teve de deixar o espaço que alugava e, ao mesmo tempo, recebeu uma proposta de mudança de sede para a cidade de Porto Alegre, capital do Estado. Portanto, no momento em que o grupo estabelece um lugar de ação, jogos, articulados e decorrentes de desdobramentos organizacionais, configuram-se para além dos aspectos do cotidiano do 
grupo. Na próxima seção dessas análises, discutimos como o estabelecimento desse lugar do circo, além das dinâmicas sociais e culturais, é interpelado por dimensões econômicas.

\section{Práticas cotidianas interpeladas pela dimensão econômica nas artes circenses}

$\mathrm{Na}$ medida em que as práticas constituem um lugar, elas circunscrevem um espaço e possuem uma positividade em relação às possibilidades de ação (FOUCAULT, 2010). Em meio a essa dinâmica, existe um caráter ético de atuação dos sujeitos que implica a recusa de identificação com a ordem ou com as leis dos fatos (CERTEAU, 1985). Esse processo abre um espaço pautado na existência histórica dos sujeitos em relação aos lugares de dominação (CERTEAU, 2002). São os desdobramentos relacionais das práticas organizacionais (SCHATZKI, 2006) no fazer artístico circense que jogam com a interpelação da dinâmica econômica, evidenciados no seguinte relato:

\begin{abstract}
A gente teve um momento difícil que foi até no ano passado assim. A gente estava sem um lugar pra treinar, sabe? E aí não conseguia ninguém que ajudasse [...] a gente procurava um espaço pra se manter. E não conseguia achar nada em Pelotas, e aí a gente conseguiu um grupo de arquitetos lá em Pelotas, uma ONG. [...] não cobram nada pra fazer o projeto. E aí eles ajudaram. Mostraram até um projeto em um antigo prédio que estava abandonado. E aí fizeram um projeto de um centro cultural, um espaço cultural, né?, e aí nisso, dentro desse centro cultural, teria o teatro do Tholl, né? E a gente, bah! Ficou triempolgado pro negócio dar certo [...] entrou na prefeitura esse projeto que foi rolando, e aí foi aprovado e tal, e aí só faltava a assinatura do prefeito. E o prefeito negou. [...] e essa foi uma das fases bem ruins do grupo. O grupo tem muita sorte [...] sempre quando entra projeto na LIC a gente ganha, na Rouanet também. Tem vários produtores que trabalham com a gente e conseguem fazer projetos muito legais assim. [...] e hoje em dia a gente tem um espaço muito legal e sem custo nenhum (Robson, acrobata, 25 anos).
\end{abstract}

De acordo com Schatzki (2006), é preciso analisar como as práticas organizacionais se articulam com a dinâmica social, para além do espaço organizacional. Robson afirma que a sobrevivência do Grupo Tholl, enquanto organização, é dependente de arbitrários econômicos, como os produtores culturais. Esses sujeitos operam na delimitação do lugar do circo nas artes, no campo social e econômico, especialmente na captação de recursos públicos e privados. Anteriormente, Robson já havia salientado em sua fala que "chegar ao nível" do Cirque Du Soleil seria também obter apoio governamental. O que se observa é que a interpelação das disputas econômicas nas artes também ocorre pelas posições que o governo ocupa nesse campo de forças.

Certeau (1999) discute que a apropriação da cultura como um campo econômico tem um dublê cômico, os governos, pois é a atuação destes que pode animar discursos ideológicos na sociedade, onde vão se concentrar "especialistas" selecionadores para determinar o que é "cultura", a exemplo dos produtores culturais. Como, no espaço das políticas públicas, as operações táticas do grupo para a sobrevivência no campo estratégico econômico encontraram entraves, eles buscaram nos laços com empresários da cidade de Pelotas formas de golpear esse sistema, operando de maneira endógena. Nesse período relatado por Robson, eles tiveram de deixar o local de treinamentos, onde pagavam aluguel, pois o prédio foi vendido à universidade da referida cidade. Mas uma empresa de transportes da cidade de Pelotas optou por ceder um galpão de sua propriedade para as atividades do grupo.

Conforme o cotidiano do circo é atravessado por questões econômicas, outras formas de disposição das ações dos sujeitos são processualmente constituídas na organização, sejam estas em suas malhas organizacionais ou no que se denomina "exterioridade" (SCHATZKI, 2006). Além dos "feitos" nos "ditos" (SCHATZKI, 2006), esse processo também vai se evidenciando por meio de relações de poder que os próprios artistas sustentam em seu cotidiano organizacional:

\footnotetext{
A gente vendo o VHS do primeiro espetáculo é muito engraçado. Porque é muito diferente, sabe? [...] Depois disso [das estreias dos espetáculos] o Tholl foi crescendo assim [...] Mesmo assim, eram apresentações esporádicas, porque o grupo não tinha tanta agenda assim. Não tinha tanto mercado pra isso (Tony, acrobata, 24 anos).
}

Destacamos que o discurso mercadológico que sustenta o sistema econômico também tem interface com as práticas do fazer artístico, especialmente com 
a necessidade de produção para atendimento de demandas de mercado. Entretanto, as atividades artísticas podem atuar de modo a driblar o sistema por dentro, ao proporcionar outras modalidades de ação aos sujeitos, além das relações de mercado. Essa dinâmica tem um caráter processual, como foi evidenciado na fala de Justine, em relação ao público dos espetáculos circenses:

E o objetivo são essas pessoas. [...] A gente tá incentivando aquela pessoa em ir mais ao teatro, estimulando aquela pessoa de ter mais contato com a arte ou pensar em fazer alguma coisa com seu corpo ou uma atividade física [...] Porque eu acho que as pessoas tão muito assim, só trabalham, não fazem nada. [...] E é legal assim quando a gente consegue ir numa plateia inteira de 800 pessoas e que uma pessoa pense assim: vou fazer alguma coisa! (Justine, acrobata, 26 anos).

As maneiras de fazer também implicam um caráter ético (CERTEAU, 1985) dos gestos políticos das artes circenses em relação ao cotidiano do público dos espetáculos. Na fala de Justine, esse gesto é objetivado nas críticas sobre as práticas materializadas no corpo, esse último objetivado para a eficiência nas relações de trabalho capitalistas, em que não há espaço para produzi-lo além da dimensão do tempo objetivo. Em termos organizacionais, a formação do circo-escola e do projeto Alegria Tholl, desenvolvidos gratuitamente pelos artistas, atuam nesse sentido de questionamentos das práticas cotidianas daqueles sujeitos não ligados às artes, constituindo o campo de ação política do Grupo Tholl.

\section{CONSIDERAÇÕES FINAIS}

Observamos, com este estudo, que alterações no cotidiano organizacional circense, a exemplo da incorporação de práticas de gestão ao fazer artístico, têm transformado o circo de um modo de vida para um campo de trabalho. Por isso, existe o movimento de regulamentação de atuação dos circos, a emergência de saberes científicos sobre essas organizações como inseridas nas indústrias criativas e a atuação de "especialistas" de cultura para classificar as formas organizacionais circenses.

Outro aspecto destacado foi a determinação dis- cursiva do posicionamento de mercado do circo com base na referência de atuação do Cirque Du Soleil, constituindo-se uma "maneira de fazer" circense em um lugar diferente do circo tradicional. Dessas mesmas práticas, emerge o sujeito produtor cultural como mediador da posição do circo no campo de seus espaços de apresentações, como nos teatros, em face da objetivação do discurso de atuação por uma demanda de mercado, configurando relações de poder no campo econômico e nas disputas com as esferas governamentais.

Essas práticas disciplinares são confrontadas por micropolíticas das práticas cotidianas do Tholl e dos gestos políticos das artes circenses. Para os artistas, o circo deve ser problematizado como parte do cotidiano da sociedade, e, objetivando essa possibilidade de expansão artística pela cidade, são desenvolvidos dois projetos de intervenção social, sem ganhos financeiros: o circo-escola e o Alegria Tholl, com intervenções artísticas em espaços institucionais. Além disso, o circo também se configura organizacionalmente pelas possibilidades de transgressões da ordem vigente, a exemplo dos processos de ingresso nele; e da constituição substantiva do trabalho do artista com base no impacto social dos espetáculos para que outros sujeitos, não imersos no cotidiano do circo, também possam ampliar suas possibilidades de ação na sociedade.

Essas formas de fazer resistência indicam possibilidades de transformação de práticas organizacionais em ação política, a exemplo da preocupação com a esfera micropolítica do corpo na recepção dos espetáculos circenses pelo público em geral. Também evidenciam lugares de ação para outras organizações que atuam com atividades artísticas, pois, como afirma Certeau (2002, p. 40), fazer resistência também é realizar bricolagens das "inúmeras e infinitesimais metamorfoses da lei, segundo seus interesses próprios e suas regras".

Como contribuições teóricas, apresentamos, neste artigo, um percurso de análise organizacional que procura realizar uma crítica ao entendimento do cotidiano como rotinização. Compreendendo o cotidiano organizacional como um espaço de práticas, dessa unidade analítica é possível discutir a gênese dos processos de gestão. Esses processos também se formam a partir de um campo de batalhas que está além do cotidiano organizacional, como no lugar próprio do circo na sociedade, sendo nos interstícios das contradições da vida cotidiana que os processos organizacionais acon- 
tecem. Salientamos a contribuição deste estudo no que se refere às análises das práticas de organização no campo das indústrias criativas, e, também, apontamos caminhos metodológicos de utilização da etnografia na captura do cotidiano organizacional.

A coexistência de lógicas de ação contraditórias em relação aos processos econômicos tem produzido clivagens nas "maneiras de fazer" circenses que extrapolam as relações de trabalho e as transformam em capacidades produtivas. Entretanto, tem provocado lógicas de ação que contrapõem esse processo de apropriação e estabelecem outros processos de organização, constituindo os circos como um processo político das práticas cotidianas.

A impossibilidade de apreensão de todas as práticas desse cotidiano organizacional limita a amplitude das conclusões aqui expostas, especialmente em relação às práticas não configuradas pelas relações de poder ou determinações externas à organização. O aprofundamento teórico que realizamos, com aproximações de discussões entre Certeau (2002), Foucault (2010) e Schatzki (2006), também pode ser contraposto em relação aos estudos que discutam as contradições entre os referidos autores. Isso viabilizará diálogos com outras pesquisas para o aprofundamento teórico-metodológico sobre o cotidiano organizacional. O caminho proposto evidencia a necessidade de se aprofundarem as análises nas lógicas de ação dos sujeitos sociais, identificando dispositivos normalizadores nas organizações, bem como formas de confronto de práticas que reconstituam os sujeitos em diferentes análises organizacionais. O cotidiano organizacional é um espaço de práticas que constituem micropolíticas em meio à esfera normativa dos processos de gestão.

O aprofundamento dessas discussões em outras organizações pode evidenciar como um conjunto de práticas de gestão é objetivado no cotidiano, a exemplo das biopolíticas, que são fenômenos seculares, mas com análises sobre suas produções contemporâneas nas organizações. As tecnologias digitais comumente discutidas com base na lógica do controle têm sido utilizadas para configurações de confrontos sociais e diferentes formas de organização dos sujeitos, e são mecanismos constituintes do cotidiano ainda não explorado nessa perspectiva.

Com efeito, essas discussões avançam no entendimento de lógicas de ação em contextos organizacionais, problematizando ações subjacentes aos arranjos das práticas e dos interstícios dos processos de ges- tão. Isso poderá contribuir para a construção de uma dimensão de análise organizacional que contemple o cotidiano de trabalho dos sujeitos sociais, as mínimas formas dos usos estratégicos e táticos do contexto social em que, como nos lembra Michel de Certeau, a "ordem é jogar".

\section{NOTA DA REDAÇÃO}

Este artigo participou do VII Encontro da Divisão de Estudos Organizacionais (ENEO), realizado em 2012 pela Associação Nacional de Pós-Graduação e Pesquisa em Administração (Anpad).

\section{REFERÊNCIAS}

ALCADIPANI, R; ROSA, A. R. O pesquisador como o outro: uma leitura pós-colonial do "Borat" brasileiro. RAE-Revista de Administração de Empresas, v. 50, n. 4, p. 371-382, 2010.

ANTONELLO, C. S; FLACH, L. Organizações culturais e a aprendizagem baseada em práticas. Cadernos EBAPE.BR, v. 9, n. 1, p. 155-175, 2011.

BENDASOLLI, P. F; BORGES-ANDRADE, J. E. Significado do trabalho nas indústrias criativas. RAE-Revista de Administração de Empresas, v. 51, n. 2, p. 143-159, 2011.

BENDASOLLI, P. F; WOOD Jr., T; KIRSCHBAUM, C; CUNHA, M. P. Indústrias criativas: definição, limites e possibilidades. RAE-Revista de Administração de Empresas, v. 49, n. 1, p. 10-18, 2009.

CASTRO, E. Vocabulário de Foucault. Tradução de Ingrid Muller Xavier. Belo Horizonte: Autêntica, 2008. 480 p.

CAVEDON, N. R. As manifestações rituais nas organizações e a legitimação dos procedimentos administrativos. 1988. 368p. Dissertação de Mestrado em Administração, Programa de Pós-Graduação em Administração da Universidade Federal do Rio Grande do Sul, Porto Alegre, 1988.

CERTEAU, M. A invenção do cotidiano: artes de fazer. Petrópolis: Vozes, 2002. 352 p.

CERTEAU, M. A cultura no plural. Petrópolis: Vozes, 1999. $256 \mathrm{p}$. 
CERTEAU, M. Teoria e método no estudo das práticas cotidianas. In: SZMRECSANYI, M. I. Q. F. (Org). Cotidiano, cultura popular e planejamento urbano. São Paulo: FAU/ USP, 1985. p. 3-17.

CLIFFORD, J. A experiência etnográfica. Rio de Janeiro: UFRJ, 2008. 320 p.

CORRADI, G; GHERARDI, S; VERZELLONI, L. Through the practice lens: where is the bandwagon of practice-based studies heading? Management Learning, v. 41, n. 3, p. 265-283, 2010.

COSTA, M. M. F. A. O velho-novo circo: um estudo de sobrevivência organizacional pela preservação dos valores institucionais. In: ENCONTRO NACIONAL DOS PROGRAMAS DE PÓS-GRADUAÇÃO EM ADMINISTRAÇÃO, 24, 2000, Florianópolis, Anais. Rio de Janeiro: ANPAD, 2000.

DREYFUS, H. L; RABINOW, P. Michel Foucault: uma trajetória filosófica. Rio de Janeiro: Forense Universitária, 2010.

FOUCAULT, M. O sujeito e o poder. In: DREYFUS, H. L; RABINOW, P. Michel Foucault: uma trajetória filosófica. Rio de Janeiro: Forense Universitária, 2010. p. 231-249.

FOUCAUlT, M. Microfísica do poder. São Paulo: Graal, 2006. 432 p.

GHERARDI, S. Telemedicine: a practice-based approach to technology. Human Relations, v. 63, n. 4, p. 501-524, 2010.

JAIME, P. Um texto, múltiplas interpretações: antropologia hermenêutica e cultura organizacional. RAE-Revista de Administração de Empresas, v. 42, n. 4 p. 72-83, 2002.

LEITE DA SILVA, A. R; CARRIERI, A. P; SOUZA, E. M. Social practices and strategizing: a study of produce merchants in the Vila Rubim market. BAR-Brazilian Administration Review, v. 8, n. 1, p. 86-106, 2011.

LINS, C. Informações estatísticas sobre os circos. Documento IBGE (INSTITUITO BRASILEIRO DE GEOGRAFIA E ESTATÍSTICA), Brasília, 2007.

O PALHAÇO. Produção de Selton Mello. Rio de Janeiro: Bananeiras Filmes, 2011, $90 \mathrm{~min}$, son, color.

OFEN, J. L. Portrait of a circus girl. Ethnography, v. 11, n. 3, p. 473-484, 2010.
PARKER, M. Organizing the circus: the engineering of miracles. Organizations Studies, v. 32, n. 4, p. 555-569, 2011.

SACCO, R. B; BRAZ, T. V. Atividades circenses: caracterização das modalidades, capacidades biomotoras, metabolismo energético e implicações práticas. Conexões - Revista da Faculdade de Educação Física, v. 8, n. 1, p.130-164, 2010.

SANDBERG, J; DALL'ALBA, G. Returning to practice new: a life-world perspective. Organization Studies, v. 30, n. 12, p. 1349-1368, 2009.

SARAIVA, E. V; CARRIERI, A. P; AGUIAR, A. R. C; BRITO, V. G. P. Um pas de deux da estratégia com a arte: as práticas do Grupo Corpo de balé. RAC-Revista de Administração Contemporânea, v. 15, n. 6, p. 1016-1039, 2011.

SATO, L; BERNARDO, M. H; OLIVEIRA, F. Psicologia social do trabalho e cotidiano: a vivência de trabalhadores em diferentes contextos micropolíticos. Psicología para América Latina, n. 15, p. 1-14, 2008.

SCHATZKI, T. R. On organizations as they happen. Organization Studies, v. 27, n. 12, p. 1863-1873, 2006.

SCHATZKI, T. R. Peripheral vision: the sites of organizations. Organization Studies, v. 26, n. 3, p. 465-484, 2005.

TEMPERANI, R. Categorias, gênero e linguagens circenses. Disponível em: http://www.portaldocirco.com.br. Acesso em 10.08.2011.

YAKHLEF, A. The corporeality of practice-based learning. Organization Studies, v. 31, n. 4, p. 409- 430, 2010. 